\title{
The total investment recovery cycle for optimal capacity allocation of the Wind-solar-battery micro-grid system
}

\author{
Guanlu Yanga, Yang Wang ${ }^{\mathrm{b}}$ and Minxu Wu \\ Huaqiao University, Xiamen 361021 ,China \\ aglyang@hqu.edu.cn, b462068741@qq.com, c979576109@qq.com
}

\section{Keywords: Micro-grid, Optimization, PSO, Recovery cycle}

Abstract. Micro-grid is a new technology approach for the distribution of distributed power generation systems into distribution systems. It can effectively integrate renewable energy (solar energy, wind energy, etc.), energy storage and loads. The issue of optimizing the capacity of the micro-grid is a very important part in the planning stage of micro-grid construction. This article use the total investment recovery cycle of the micro-grid as the optimization goal,and construct an independent operation micro-grid power optimization configuration model with wind power, PV power generation and battery storage devices.It uses the number of power supply installations in the micro-grid as optimization variables. And particle swarm optimization is used to solve the optimal capacity configuration model of micro grid .The example results verify the validity of the model and algorithm.

\section{Introduction}

In the optimization of the capacity of the micro-grid, it is necessary to consider factors such as economy, environmental protection, and operational stability in the construction of the micro-grid. At present, some scholars at home and abroad have carried out research on the optimal configuration of micro-grid capacity. The literature [1] studied the mathematical modelling and economic analysis of the wind and solar storage system and studied the optimal capacity allocation of the independently operating micro-grid. The literature [2] studied the interconnections among various components in the micro-grid, and studies the optimization of single-objective and multi-objective micro-grid capacity by constructing different objective functions.

This paper studies the optimal configuration of micro-grid power capacity for independent operation throughout the year including wind generators, photovoltaic arrays, and energy storage devices. Taking the total investment recovery cycle as the objective function and the power supply reliability as constraints, the capacity optimization configuration of the micro-grid is transformed into a multi-constraint nonlinear integer programming problem. The particle swarm algorithm is used to solve the model.

\section{Wind-PV-Storage micro-grid Model}

In order to calculate the optimal capacity configuration of a wind and solar storage micro-grid, it is first necessary to establish an accurate mathematical model for the micro-grid. This paper mainly considers the power and energy during wind power generation, photovoltaic power generation, and battery charging and discharging, and establishes its mathematical model.

Wind turbine model

The approximate relationship between wind turbine output power and wind speed can be described by equation (1):

$$
P_{\mathrm{wt}}=\left\{\begin{array}{cc}
0, & \left(v<v_{c} \text { 或 } v>v_{F}\right) \\
P_{\mathrm{N}} \frac{v^{\mathrm{k}}-v_{c}^{k}}{v_{R}^{k}-v_{c}^{k}}, & \left(v_{c} \leq v \leq v_{R}\right) \\
P_{R}, & \left(v_{R}<v \leq v_{F}\right)
\end{array}\right.
$$

Among them, $P_{N}$ is the rated power of wind turbine, $v_{c}$ is the cut-in wind speed, $v_{R}$ is the rated wind speed, $v_{F}$ is the cut-out wind speed, and $k$ is the Weibull shape parameter. 
The shape parameters of the Weibull distribution can be approximated by the average wind speed $\bar{v}$ and standard deviation of wind speed $\sigma$.

Photovoltaic array model

The actual output power of the PV array can be calculated from the output power under standard rated conditions, the actual light intensity and the ambient temperature:

$$
P_{P V}=P_{S T C} \frac{G_{c}}{G_{S T C}}\left[1+k\left(T_{c}-T_{S T C}\right)\right]
$$

In the formula, $P_{P V}$ is the output power of the working point; $G_{S T C}$ is the light radiation intensity under the standard condition, take $1 \mathrm{~kW} / \mathrm{m}^{2} ; G_{c}$ is the actual received light radiation intensity; $P_{S T C}$ is the rated power output by the photovoltaic array under the standard environmental conditions; $k$ is the power temperature coefficient, and $T_{S T C}$ is the surface temperature of the component under the standard condition, and the surface temperature of the component is $25^{\circ} \mathrm{C} ; T_{c}$ is the working point. The photovoltaic cell used in this article has a rated power of $100 \mathrm{~W}$.

Battery Model

The actual available battery capacity $E_{b a t}$ is a function of the battery temperature:

$E_{b a t}=E_{S T C}\left[1+\delta_{B}\left(T_{b a t}-T_{\text {batsTC }}\right)\right]$

In the formula: $T_{b a t}$ is the operating point battery temperature, the ambient temperature can be used instead; $E_{S T C}$ is the rated capacity of the battery under standard conditions, usually manufacturers to provide parameters; standard conditions, temperature $T_{\text {batSTC }}$ is $25 ; \delta_{B}$ is the capacity temperature coefficient, usually $0.6 \%$.

\section{Establishment of objective function and constraints}

The topic established a mathematical model of wind and solar storage microgrid with fans, photovoltaic arrays, and batteries. Through the calculation and selection of reasonable wind-storage capacity ratios, the investment cost recovery cycle of the system was used as an objective function to optimize the configuration. The simulation time for the operation of the power supply system is 1 year, and the minimum time interval is 1 hour. Meteorological data and load data are used to calculate the output of each power supply. At the same time, the system reliability index and energy excess rate are calculated, and the system investment recovery cycle is used as an objective function. Solve the above nonlinear programming problem.

The cost function (CF) of this model is as follows:

$$
\min T(X)=\frac{\sum_{i=1}^{3}\left(C_{\text {capi }} \cdot x_{i}+C_{\text {Aomi }} \cdot x_{i}+C_{\text {Arepi }} \cdot x_{i}\right)}{C_{1}(1-L P S P) \sum_{i=1}^{8760} P_{i}}
$$

In the formula: $C_{\text {capi }}$ is the equipment investment cost of the system's i-th power supply; $C_{\text {Aomi }}$ is the installation and maintenance cost of the system's i-th power source; $C_{\text {Arep }}$ is the replacement cost of the system's $\mathrm{i}$-th power source; $i$ is the number of power source types; $X=\left[x_{1}, x_{2}, \cdots, x_{i}\right]$ is the decision variable; $x_{i}$ is the number of the $\mathrm{i}$-th power supply, and $C_{1}$ is the power price.

For the establishment of constraint conditions, this article mainly has four parts of constraints: micro power generation constraints, capacity constraints of energy storage equipment, power load balance constraints and reliability constraints.

Micro power generation constraints

For microgrids, the capacity of each power supply in the micro-grid cannot exceed the maximum capacity at the time of planning.

$$
X_{k} \leq X_{k \cdot \max }
$$

In the formula, $X_{k \text { max }}$ is the upper limit of the i-th micro-source (including energy storage equipment) of the micro-grid. 
Energy storage equipment capacity constraints

Energy storage equipment as a key equipment to balance the difference between micro power supply power output and load demand, its frequent use will shorten the life, pollute the environment, so in order to improve the service life of energy storage equipment and reduce environmental pollution, should be in the process of its operation The following conditions:

$S O C_{\min } \leq S O C \leq S O C_{\max }$

In the formula: $S O C$ is a very important decision variable of the energy storage device. By constraining the $S O C$ value, it can effectively prevent the battery from being over-charged and over-discharged. The allowable range of the battery's state of charge is usually when $S O C$ reaches the maximum value of the battery.

Power load balance constraints

For the entire system, at any time, the sum of the power emitted by all micro-sources at time $t$ in the micro-network is not less than the load of the $\mathrm{t}$-th time period.

$$
\sum_{1}^{N_{s}} P_{k}(t) \geq P(t)
$$

In the formula: $N_{s}$ is the number of microgrid micropower supplies (including energy storage cells).

\section{Reliability constraints}

The loss of power supply probability (LPSP) is used as a reliability evaluation index. LPSP stands for the power supply reliability of the system and is defined as:

$$
L P S P=\frac{\sum_{t=1}^{T} S_{\text {loss }}(t)}{T}
$$

In the formula: $S_{\text {loss }}(t)$ indicates whether the system is lack of electricity, a value of 1 indicates the lack of power of the system ( the total power provided by the system at time $t$ is less than the system load demand). A value of 0 indicates that the system can meet all load requirements.

\section{Simulation results}

Particle swarm optimization (PSO) is essentially an iterative random search algorithm with parallel processing and good robustness. The optimal configuration of the actual microgrid system capacity also requires meteorological data and load data at the project site. The simulation time for the operation of the power supply system is 1 year, and the minimum time interval is 1 hour. The output of each power supply is calculated from the meteorological data and load data. At the same time, the reliability indices and excess energy ratio of the system are calculated and the annual investment cost is targeted. Function to solve the above nonlinear programming problem.

This project uses the conventional microgrid as a model to carry out the optimal design for combined wind and solar power generation. The meteorological data of this implementation site are shown in Figure 1to Figure3, and the annual load curve is shown in Figure 4.

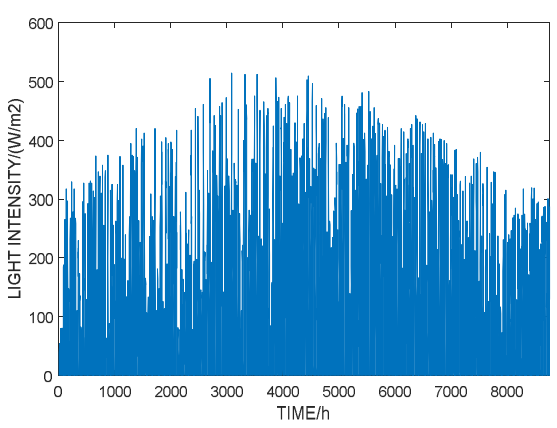

Figure 1 Annual light intensity curve of the power generation system

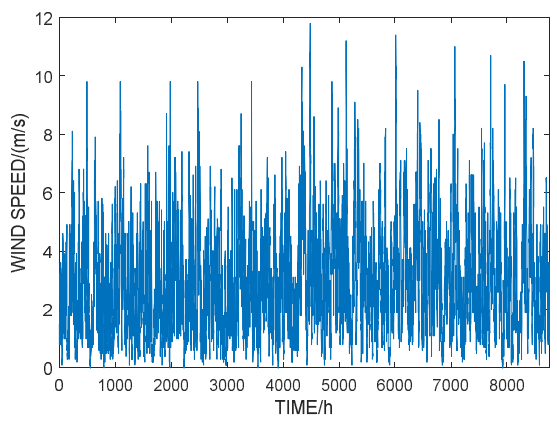

Figure 2 Annual wind speed curve of the power generation system 


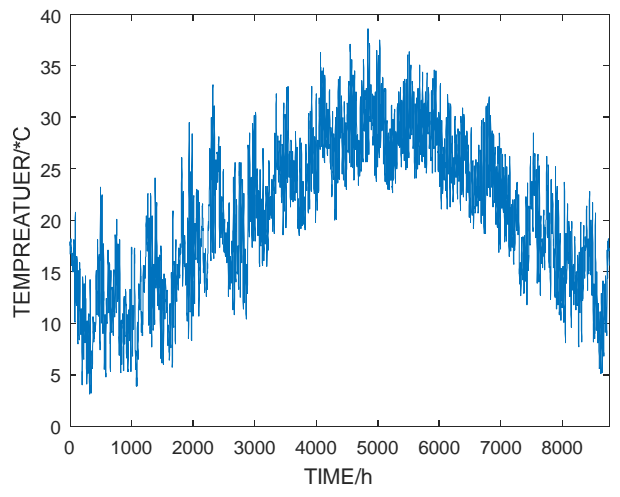

Figure 3 Annual tempreature curve of the power generation system

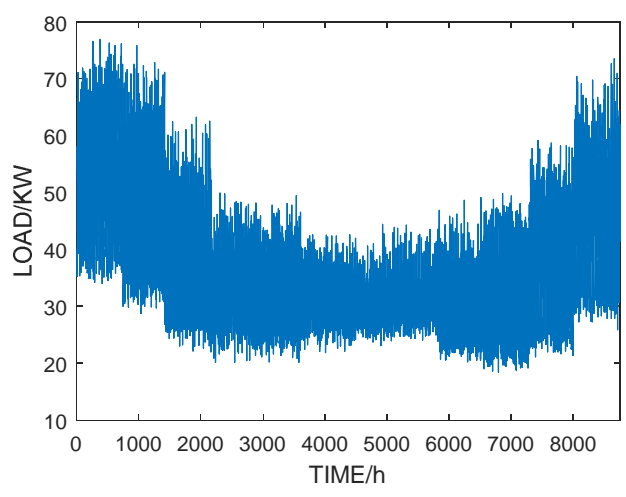

Figure 4 Annual load curve of the powe generation system

This paper uses the PSO to obtain the global optimal solution for the optimal allocation of combined power supply capacity for wind and solar energy storage. The energy control strategy for this design is shown in Figure 5.

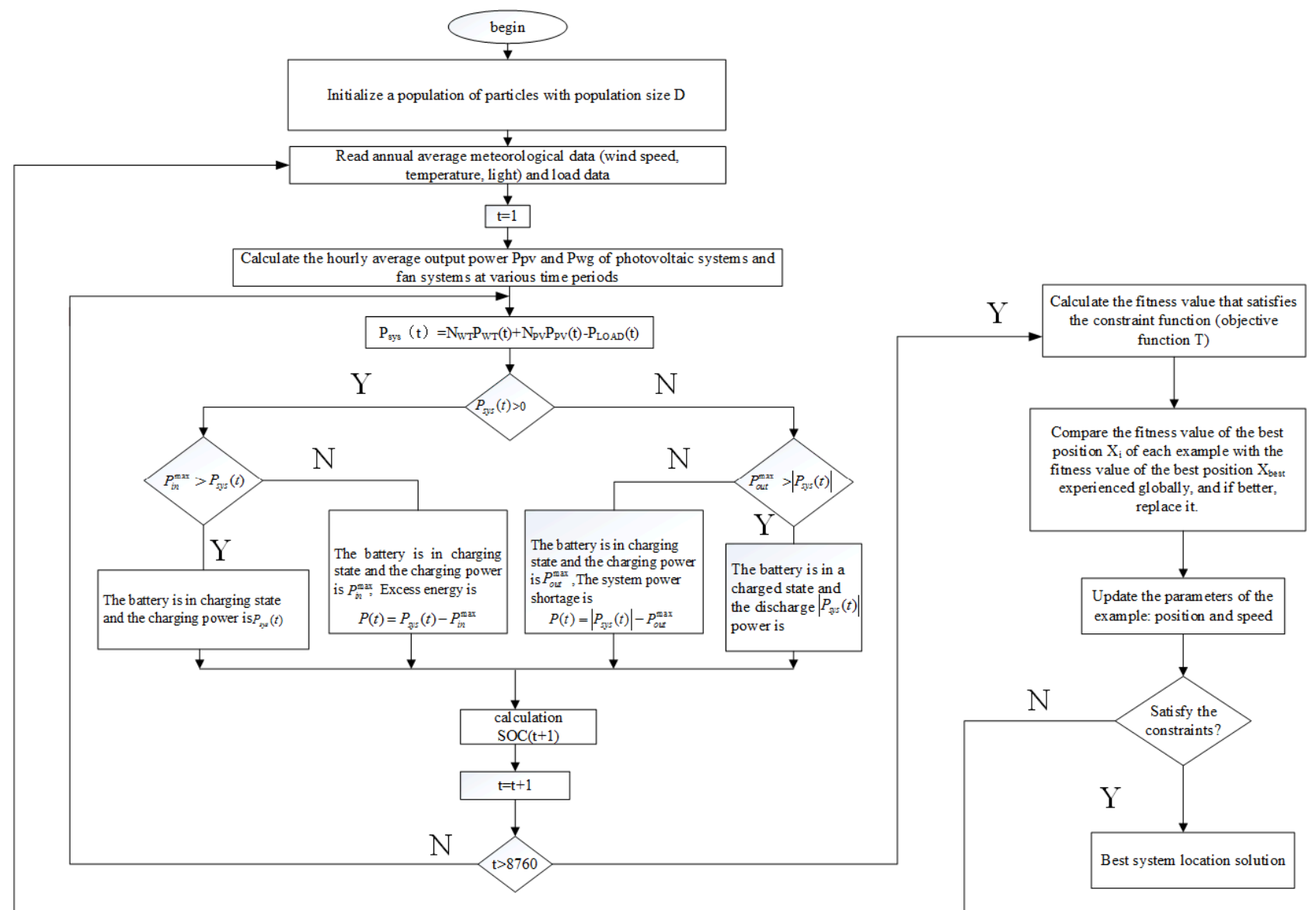

Figure 5 The energy control strategy for this design

This article through the programming calculation in MATLAB, the simulation results shown in table 1 , the constraint condition of the power shortage rate is set to 0 , the results of this calculation is 13.9 years. The algorithm iteration diagram is shown in Figure 6. 
table 1 simulation results

\begin{tabular}{cccccc}
\hline $\begin{array}{c}\text { Progra } \\
\mathrm{m}\end{array}$ & $\begin{array}{c}\text { Wind } \\
\text { Turbines }\end{array}$ & $\begin{array}{c}\text { Photovoltaic } \\
\text { panel }\end{array}$ & $\begin{array}{c}\text { storage } \\
\text { battery }\end{array}$ & LPSP & $\begin{array}{c}\text { Collecting } \\
\text { Cycles }\end{array}$ \\
\hline 1 & 30 & 304 & 262 & 0.00 & 13.9 \\
2 & 30 & 287 & 315 & 0.10 & 13.1 \\
\hline
\end{tabular}

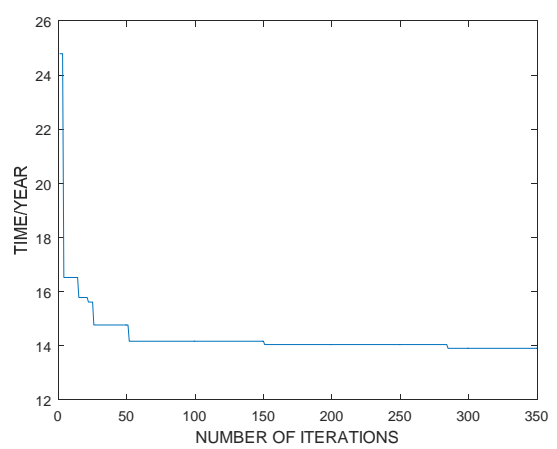

Figure 6 algorithm iteration diagram

\section{Conclusions}

This paper proposes a method to solve the micro-grid capacity optimization problem of hybrid wind and solar energy storage using particle swarm optimization. It comprehensively considers the randomness and volatility of wind energy, solar energy, and the charge and discharge characteristics of batteries to optimize the capacity of micro-grid for wind and solar storage.

\section{Acknowledgements}

This work was financially supported by National Science and Technology Support Program(2015 BA107b04) and Fujian Province Science and Technology Plan Project (2014H0031), People's Rep ublic of China.

\section{References}

[1] Belfkira $\mathrm{R}$,Zhang L ,Barakat G.Optimal sizing of hybrid wind/PV/diesel power generation unit[J].Solar Energy,2011,12(1):100-110.

[2] Tafreshi S M M, Zamanni H A, Ezzati S M, et al. Optimal unit sizing of distributed energy resources in micro grid using genetic algorithm[C]//18th ICEE Conference.Isfahan, Iran: 18th ICEEConference,2010:836-841.

[3] Fatemeh Jahanbani Ardakani, Gholamhossein Riahy, Mehrdad Abedi .Design of an optimum hybrid renewable energy system considering reliability indices[C]//Electrical Engineering (ICEE),2010:842-847.

[4] HUANG You-rui.Intelligent optimization algorithms and its application[M].Beijing:National Defense Industry Press,2008.

[5] Testa A,de Caro S,La Torre R,et al.Optimal design of energy storage systems for stand-alone hybrid Wind/PV generators[C]//Power Electronics Electrical Drives Automation and Motion(SPEEDAM),2010 International Symposium on,2010:1291-1296

[6] Pouresmaeil E, Miguel-Espinar C,Massot-Campos M,et al.A control technique for intergration of DG units to the electrical network[J]. IEEE Trans on Industrial Electronics,2013,60(7):2881-2893. 